\title{
MLH1 and MSH2 Gene Mutations and Polymorphisms in Six Malay Families with Hereditary Nonpolyposis Colorectal Cancer
}

Wan Khairunnisa Wan Juhari ${ }^{1}$, BSc, Khairul Bariah Ahmad Amin Noordin ${ }^{4}$, PhD, Wan Faiziah Wan Abdul Rahman $^{2}$, MPath, Andee Dzulkarnaen Zakaria ${ }^{3}$, MMed, Ahmad Shanwani Mohd Sidek ${ }^{5}$, MMed, Muhammad Radzi Abu Hassan ${ }^{6}$, MRCP, MMed, Finlay Macrae ${ }^{7}$, MD,FRACP, FRCP, AGAF, Bin Alwi Zilfalil, MMed, PhD ${ }^{1^{*}}$

${ }^{1}$ Department of Pediatrics, School of Medical Sciences, Universiti Sains Malaysia, Health Campus, Kelantan, Malaysia

${ }^{2}$ Department of Pathology, School of Medical Sciences, Universiti Sains Malaysia, Health Campus, Kelantan, Malaysia

${ }^{3}$ Department of Surgery, School of Medical Sciences, Universiti Sains Malaysia, Health Campus, Kelantan, Malaysia

${ }^{4}$ School of Dental Sciences, Universiti Sains Malaysia, Health Campus, Kelantan, Malaysia

${ }^{5}$ Surgery Department, Hospital Raja Perempuan Zainab 2, Kota Bharu, Malaysia

${ }^{6}$ Clinical Research Centre, Hospital Sultanah Bahiyah, Kedah, Malaysia

${ }^{7}$ Department of Colorectal Medicine and Genetics, Royal Melbourne Hospital, Melbourne, Australia

\begin{abstract}
Background: Hereditary nonpolyposis colorectal cancer (HNPCC) also known as Lynch syndrome is commonly caused by genetic alterations in any of the four mismatch repair (MMR) genes; MLH1, MSH2, MSH6 and PMS2. This is the first study aimed to investigate genetic variants in Malay HNPCC families. Methods: Six Malay HNPCC families who fulfilled any of the Bethesda criteria were recruited into this study. A total of $3 \mathrm{ml}$ of blood was withdrawn from each patient in the families. The samples were further analyzed using polymerase chain reaction and direct sequencing of the selected exons of MLH1 and MSH2 genes. Results: Two missense mutations and four single nucleotide polymorphisms (SNPs) were identified in six patients. These variants in the MLH1 and MSH2 genes were identified in four families who met the revised Bethesda guidelines. In two families, no mutation and polymorphism was identified in both the exon and intron of the respective genes. Of the mutations and polymorphisms identified, five have never been reported in Malay HNPCC families before. A missense mutation was detected in exon 5 of the MLH1 gene, C.394G>C (p.Asp132His) and four mutations and polymorphisms were detected in the MSH2 gene; heterozygous c. $211+98 T>C$ and $C .211+9 C>G$ and homozygous $C .211+98 T>C$ and $C .211+9 C>G, C .367-86 A>C$ and $C .382 C>G$. Conclusion: The results represented a new spectrum of mutations and polymorphisms in the Malay HNPCC families. However, a larger study involving additional families and analysis is required to determine the impact and nature of the identified mutations and polymorphisms.
\end{abstract}

KEYWORDS: Hereditary Nonpolyposis Colorectal Cancer, MLH1, MSH2, Malay

\section{INTRODUCTION}

Hereditary Nonpolyposis Colorectal Cancer (HNPCC), also known as Lynch Syndrome, was first introduced as a hereditary cancer syndrome in the mid-1960s (Lynch et al. 1966). It is the most common hereditary colon cancer syndrome, and accounts for $2-3 \%$ of the total colon cancers (Ghee, 2014). HNPCC is commonly associated with several characteristics, including earlier age of diagnosis

Corresponding author:

Bin Alwi Zilfalil,

Department of Pediatrics,

School of Medical Sciences,

Universiti Sains Malaysia, Health Campus

16150 Kota Bharu, Kelantan

Email: zilfalil@usm.my

Tel No.: +6097676531

Fax No.: +6097676543 and high rates of multiple primary cancers; colorectal, endometrial, ovarian, stomach, hepatobiliary, urinary, small bowel, brain/central nervous system and sebaceous tumors. ${ }^{4}$ Genetic factors may contribute to the predisposition of HNPCC, an autosomal dominantly inherited genetic condition, caused by germline mutations in any of the common mismatch repair (MMR) genes; MLH1, MSH2, MSH6 and PMS2, which produce the MMR proteins. These genes play a significant role in the repair of DNA errors in one or a few base pairs, resulting in the loss of MMR function which leads to various mutations including microsatellite instability. ${ }^{4,21}$ Mutations in MLH1 and MSH2 account for almost $90 \%$ of the identified cases. ${ }^{6,9}$

The spectrum of cancer risk may relate to the cancer-specific genes, where MSH2 mutation carriers may have a higher risk of extra colonic cancers than the MLH1 mutation carriers. ${ }^{7}$ Previously, pedigree 
analysis was used to diagnose HNPCC before the discovery of the MMR genes; now the cancer risk is based on the gene carrier status. ${ }^{14}$ In Malaysia, the revised Bethesda criteria that assesses the pedigree, has been used in several studies of HNPCC as the criteria for patient' selection. ${ }^{22,26}$

To date, there are almost 14,800 known different germline mutations for HNPCC, with many published in the International Society of Gastrointestinal Hereditary Tumours (InSiGHT) database (http:// www.insight-group.org/). There has been no published study examining HNPCC familial mutations specific to the Malay population, which is the biggest ethnic group in Malaysia. This study is the first known study which investigates HNPCC familial mutations in Malay HNPCC patients and their family members, with comparisons being made to the available HNPCC international and national data bases.

\section{MATERIALS AND METHODS}

\section{HNPCC families}

Six families with a total number of twelve patients who fulfilled any one or more of the Bethesda criteria: 1) colorectal cancer (CRC) diagnosed in a patient $<50$ years old, 2) presence of synchronous, metachronous colorectal or other Lynch syndromerelated tumours regardless of age, 3 ) a patient with CRC and a first-degree relative with a Lynch syndrome-related tumour, with one of the cancers diagnosed at age $<50$ years old, 4) Patient with CRC with two or more first degree relatives or second degree relatives with a Lynch syndrome-related tumour (colorectal, endometrial, stomach, ovarian, pancreas, ureter, renal pelvis, biliary tract and brain tumours, sebaceous gland adenomas and keratoacanthomas, and carcinoma of the small bowel) regardless of age, were recruited from three local hospitals: Hospital Universiti Sains Malaysia, Hospital Raja Perempuan Zainab 2, Kota Bharu, Kelantan and Hospital Sultanah Bahiyah, Alor Setar, Kedah. The selection of the Malay families were also based on at least three generations of the same ethnicity and the family history of each patient was assessed based on an interview with patients who came for regular clinical treatment and was further confirmed by the medical records.

This study was approved by the Research and Ethics Committee, Universiti Sains Malaysia and the Medical Research and Ethics Committee (MREC), Ministry of Health, Malaysia. Informed consent was sought from all patients. A total of $3 \mathrm{ml}$ of blood was withdrawn from each patient for germline mutation screening.

\section{DNA extraction}

Peripheral blood was isolated using a commercially available DNA extraction kit, QIAmp DNA Blood Mini kit (Qiagen, Hilden, Germany) according to the manufacturer's protocols.

Screening of germline mutations and polymorphisms in $\mathrm{MLH} 1$ and $\mathrm{MSH} 2$ genes

Six exons of MLH1 and MSH2, respectively, were amplified by using conventionally designed primers from the MLH1 and MSH2 gene sequences obtained from the NCBI Reference Sequence database ${ }^{28}$ and the Genatlas database ${ }^{29}$ and verified using NCBI Primer-BLAST. ${ }^{25}$ The details of the primers are listed in Table 1. The mutations and polymorphisms in $\mathrm{MLH} 1$ and $\mathrm{MSH} 2$ were detected by amplifying individual exons and the flanking intron sequences by polymerase chain reaction (PCR) using the respective primers of $\mathrm{MLH} 1$; exons/introns $1,2,5$, 7, 12 ,17, 18 and MSH2; exons/introns 1, 3, 5, 6, 7, 8, 12.

Table 1 List of primers of MLH1 and MSH2 gene and their respective size of PCR products used in PCR amplification reaction

\begin{tabular}{|c|c|c|}
\hline & Primer sequences ( $5^{\prime}$ to $\left.3^{\prime}\right)$ & $\begin{array}{l}\text { Expected } \\
\text { size of } \\
\text { PCR } \\
\text { product } \\
\text { (bp) }\end{array}$ \\
\hline $\begin{array}{l}\text { Intron/ } \\
\text { Exon } 1\end{array}$ & $\begin{array}{l}\text { 5'gttgagaaatttgactggcattc 3' } \\
\text { 5'gttaagtcgtagcccttaagtg 3' }\end{array}$ & 337 \\
\hline $\begin{array}{l}\text { Intron/ } \\
\text { Exon } 2\end{array}$ & $\begin{array}{l}\text { 5' ggcactattgtttgtatttggag } 3^{\prime} \\
5 \text {, catctgcaaaagcctagtttcc } 3 \text {, }\end{array}$ & 290 \\
\hline $\begin{array}{l}\text { Intron/ } \\
\text { Exon } 5\end{array}$ & $\begin{array}{l}\text { 5'ccaattcaaatgattatggaagtag 3' } \\
\text { 5' cttcaacaatttactctcccatg 3' }\end{array}$ & 282 \\
\hline $\begin{array}{l}\text { Intron/ } \\
\text { Exon } 7\end{array}$ & $\begin{array}{l}\text { 5' ggctctgacatctagtgtgtg } 3 \text {, } \\
5, \text { taacatcagctactgtctctcc } 3 \text {, }\end{array}$ & 280 \\
\hline $\begin{array}{l}\text { Intron/ } \\
\text { Exon } 12\end{array}$ & $\begin{array}{l}5 \text { ' gctccatttggggacctgtat } 3^{\prime} \\
5 \text {, gaataaaggaggtaggctgtac } 3 \text {, }\end{array}$ & 517 \\
\hline $\begin{array}{l}\text { Intron/ } \\
\text { Exon } 17\end{array}$ & $\begin{array}{l}\text { 5' gagtggcagataggagcacaa 3' } \\
\text { 5' cttatcatctttatcattccagatc } 3 \text {, }\end{array}$ & 301 \\
\hline $\begin{array}{l}\text { Intron/ } \\
\text { Exon } 18\end{array}$ & $\begin{array}{l}\text { 5' gtagtctgtgatctccgtttag } 3^{\prime} \\
\text { 5' gagatgggcaagtttcatctc } 3^{\prime}\end{array}$ & 272 \\
\hline $\begin{array}{l}\text { Amplifying } \\
\text { region } \\
\text { (MSH2 } \\
\text { gene) }\end{array}$ & Primer Sequences ( $5^{\prime}$ to $3^{\prime}$ ) & $\begin{array}{l}\text { Expected } \\
\text { size of PCR } \\
\text { product } \\
\text { (bp) }\end{array}$ \\
\hline $\begin{array}{l}\text { Intron/ } \\
\text { Exon } 1\end{array}$ & $\begin{array}{l}\text { 5' gcattttcttcaaccaggaggt 3', } \\
\text { 5' cggaatccgcacaagcaccaa 3, }\end{array}$ & 388 \\
\hline $\begin{array}{l}\text { Intron/ } \\
\text { Exon } 3\end{array}$ & $\begin{array}{l}\text { 5' agaatcgattgaacccttga 3' } \\
\text { 5' caattaaagagcctttcctaggc 3, }\end{array}$ & 552 \\
\hline $\begin{array}{l}\text { Intron/ } \\
\text { Exon } 5\end{array}$ & $\begin{array}{l}\text { 5' gaactggatccagtggtataga 3', } \\
\text { 5' tagctcctttataagcttcttcag 3, }\end{array}$ & 301 \\
\hline $\begin{array}{l}\text { Intron/ } \\
\text { Exon } 6\end{array}$ & $\begin{array}{l}\text { 5' gtaaggttttcactaatgagcttg } 3^{\prime} \\
5 \text { ' tatgtactctgtacagttaaatgg } 3 \text {, }\end{array}$ & 314 \\
\hline $\begin{array}{l}\text { Intron/ } \\
\text { Exon } 7\end{array}$ & $\begin{array}{l}\text { 5' gagctgatttagttgagacttac 3', } \\
\text { 5' caccaccaccaactttatgagg 3' }\end{array}$ & 379 \\
\hline $\begin{array}{l}\text { Intron/ } \\
\text { Exon } 8\end{array}$ & $\begin{array}{l}\text { 5' ggatcaaatgatgcttgtttatct 3' } \\
\text { 5' cacaaaggtgctacaattagatac } 3 \text {, }\end{array}$ & 317 \\
\hline $\begin{array}{l}\text { Intron/ } \\
\text { Exon } 12\end{array}$ & $\begin{array}{l}\text { 5' cggcttatatctgtttattattcag 3' } \\
\text { 5' cctttctaatgttaagaactggg } 3{ }^{\prime}\end{array}$ & 435 \\
\hline
\end{tabular}


PCR was performed in a $25 \mu \mathrm{l}$ reaction using the specific primers of $M L H 1$ and $M S H 2$ respectively. The PCR amplification was carried out in a total reaction of $25 \mu$ consisting: 1) $1 \mathrm{X}$ reaction buffer (Promega, USA), 2) $1.5 \mathrm{mM} \mathrm{MgCl} 2$ (Promega, USA), 3) $0.2 \mathrm{mM}$ dNTPs (Promega, USA), 4) $0.2 \mu \mathrm{mol}$ each of forward and reverse primers (IDT, Singapore), 5) 0.05 unit of GoTaq DNA Polymerase (Promega, USA) and 6) $\sim 50 \mathrm{ng}$ of genomic DNA. PCR was performed with an initial denaturation step at $95^{\circ} \mathrm{Cfor} 5 \mathrm{~min}$, followed by 35 cycles of denaturation at $94{ }^{\circ} \mathrm{Cfor} 1$ min, annealing at the respective temperatures for all the studied exons for $1 \mathrm{~min}$ and extension at 72 ${ }^{\circ}$ Cfor 2 min, followed by a final extension step at 72 ${ }^{\circ} \mathrm{Cfor} 3 \mathrm{~min}$. The amplicons were then visualized by gel electrophoresis on $2 \%$ agarose gel. The amplicons were then purified using the QIAGEN QIAmp PCR purification kit (Qiagen, Hilden, Germany) prior to Sanger sequencing. The purified amplicons were sequenced using the ABI PRISM BigDye Terminator Cycle Sequencing Ready Reaction Kit (Perkin-Elmer, Applied Biosystems Division, USA). The sequencing was performed by the Centre for Chemical Biology sequencing service (Penang, Malaysia). The sequencing data were visualized and analyzed by using the BioEdit software ${ }^{27}$ to confirm the presence of genetic variations in each patient's sample.

\section{RESULTS}

A total of twelve Malay patients from six Malay HNPCC families were enrolled in this study. All of the patients in each family were known to be a first -degree relative to one another as is shown in Table 2. Two missense mutations and four single nucleotide polymorphisms (SNPs) were identified in six patients. The two missense mutations were identified in exon 5 of the MLH1 gene, c.394G>C (D132H) (Fig. 2a; Fig. 3b) and exon 3 of the MSH2 gene; c.382C>G (Fig. 2c; Fig. $3 a)$. Three SNPs were identified in the intronic region of the $\mathrm{MSH} 2$ gene; C. $211+98 \mathrm{~T}>\mathrm{C}$ (intron 1), C. $211+9 C>G$ (intron 1) and C.367-86A>C (intron 3) including one promoter polymorphism found in the MLH1 gene, c. $-93 \mathrm{G}>\mathrm{A}$. The successful amplification product for each SNP in the MSH2 gene is shown in Figure $2 \mathrm{~b}$ and $2 \mathrm{c}$ respectively. A patient, $\mathrm{F6}$, in Family A displayed locus heterozygosity in C. $211+98 T>C$ and $c .211+9 C>G$, however, his son, $F 1$, did not harbor similar polymorphisms (Table 2). However, in Family B, only one patient, F7, who is mother to F4 displayed homozygosity in intron 1 of MSH2 (Table 2). Among the six families, only Family $F$ from which the daughter (F21) who was diagnosed with CRC at the age of 26 years old and her mother who was an ovarian cancer patient (Fig. 1b), harbored three similar polymorphisms in MLH1; C. $-93 \mathrm{G}>\mathrm{A}$ and MSH2 genes; C.211+98T>C and demonstrated loss of $\mathrm{MLH} 1$ and $\mathrm{MSH} 2$ expressions. c. $211+9 C>G$. We previously reported no loss of expression in patients carrying the variants as evidenced by immunohistochemical staining. ${ }^{22}$ Only immunohistochemical staining on patient F22.

Four patients from three distinct families, Family A, E and $F$ respectively, reported a polymorphism, c.93G $>A$ in the promoter region of MLH1. However, our results showed that two families, Family $C$ and $D$ have

a)

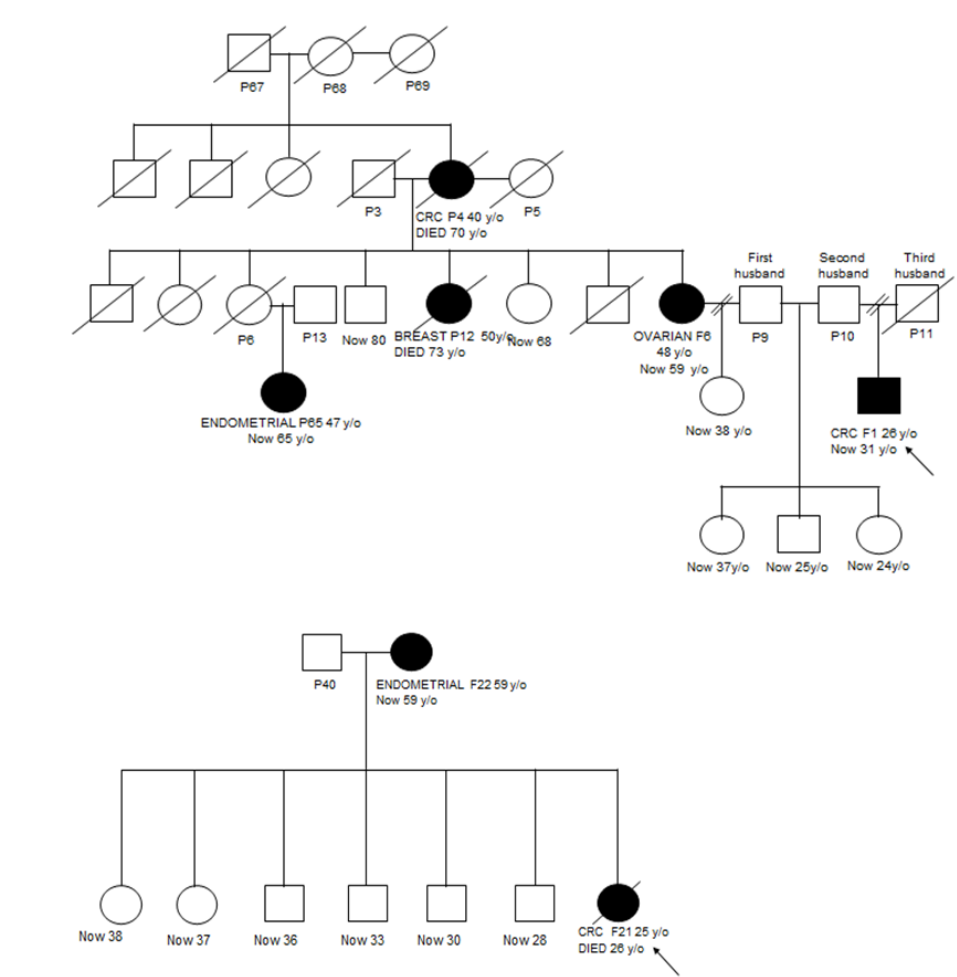

Figure 1 Family pedigree of a) Family A ( $F 1$ a CRC patient is the son of F6 who is an ovarian cancer patient); b) Family F(F21 is a daughter diagnosed with CRC also known to have a mother, F22, who is an ovarian cancer patient). 
Table 2 Mutations and polymorphisms identified in Malay HNPCC families

\begin{tabular}{|c|c|c|c|c|c|}
\hline Family & $\begin{array}{l}\text { Patient ID/ } \\
\text { Patient's } \\
\text { relationship }\end{array}$ & $\begin{array}{l}\text { Age of } \\
\text { diagnosis/ } \\
\text { Gender }\end{array}$ & $\begin{array}{l}\text { Patient } \\
\text { survival (Last } \\
\text { known age) }\end{array}$ & $\begin{array}{l}\text { Clinical } \\
\text { presentations }\end{array}$ & $\begin{array}{l}\text { Mutation(s)/Polymorphism(s) } \\
\text { identified }\end{array}$ \\
\hline \multirow[t]{2}{*}{$\mathbf{A}$} & F1/Son & $26 / M$ & 27 (Alive) & CRC & MLH1 : 5'UTR c.-93G>A \\
\hline & F6/Mother & $50 / \mathrm{F}$ & 55 (Alive) & Ovarian cancer & $\begin{array}{l}\text { MSH2 : Intron } 1 \text { heterozygous } \\
\text { c. } 211+98 T>C \text { and c. } 211+9 C>G \text {; } \\
\text { Intron } 3, \text { c. } 367-86 A>C \text {; Exon } 3 \text {, } \\
\text { c. } 382 C>G \text { (p. Leu128Val) }\end{array}$ \\
\hline \multirow[t]{2}{*}{ B } & F4/Daughter & $27 / F$ & 28 (Alive) & CRC & $\begin{array}{l}\text { No mutation/polymorphism } \\
\text { identified }\end{array}$ \\
\hline & F7/Mother & $53 / F$ & 56 (Alive) & CRC & $\begin{array}{l}\text { MSH2 : Intron } 1 \text { homozygous } \\
\text { c. } 211+9 C>G\end{array}$ \\
\hline \multirow[t]{2}{*}{ C } & $\begin{array}{l}\text { F5/Fifth } \\
\text { sister }\end{array}$ & $43 / F$ & 44 (Alive) & CRC & $\begin{array}{l}\text { No mutation/polymorphism } \\
\text { identified }\end{array}$ \\
\hline & $\begin{array}{l}\text { F8/Second } \\
\text { sister }\end{array}$ & $58 / \mathrm{F}$ & 60 (Alive) & CRC & $\begin{array}{l}\text { No mutation/polymorphism } \\
\text { identified }\end{array}$ \\
\hline \multirow[t]{2}{*}{ D } & $\begin{array}{l}\text { F10/ } \\
\text { Daughter }\end{array}$ & $29 / \mathrm{F}$ & 32 (Alive) & CRC & $\begin{array}{l}\text { No mutation/polymorphism } \\
\text { identified }\end{array}$ \\
\hline & F12/Mother & $50 / F$ & 56 (Alive) & CRC & $\begin{array}{l}\text { No mutation/polymorphism } \\
\text { identified }\end{array}$ \\
\hline \multirow[t]{2}{*}{ E } & $\begin{array}{l}\text { F14/Eldest } \\
\text { brother }\end{array}$ & $54 / M$ & 61 (Alive) & CRC & $\begin{array}{l}\text { No mutation/polymorphism } \\
\text { identified }\end{array}$ \\
\hline & $\begin{array}{l}\text { F15/ } \\
\text { Youngest } \\
\text { brother }\end{array}$ & $39 / M$ & 42 (Died) & CRC & MLH1 : 5' UTR c.-93G>A \\
\hline \multirow[t]{2}{*}{$\mathbf{F}$} & $\begin{array}{l}\text { F21/ } \\
\text { Daughter }\end{array}$ & $25 / F$ & 26 (Died) & CRC & $\begin{array}{l}\text { MLH1 : Heterozygous 5'UTR c. } \\
\text { 93G }>\text { A; exon } 5 \text { c. } 394 G>C \\
\text { (p.Asp132His) } \\
\text { MSH2 : Intron } 1 \text { heterozygous } \\
\text { c. } 211+98 T>C \text { and c. } 211+9 C>G\end{array}$ \\
\hline & F22/Mother & $59 / F$ & 59 (Alive) & Endometrial cancer & $\begin{array}{l}\text { MLH1: Heterozygous 5'UTR c. } \\
93 G>A \\
\text { MSH2 : Intron } 1 \text { heterozygous } \\
\text { c. } 211+98 T>C \text { and } c .211+9 C>G\end{array}$ \\
\hline
\end{tabular}

*Abbreviations:

M: Male

F: Female

CRC: Colorectal cancer

no mutation and polymorphism. All of the patients (F1, F4, F5, F10, F15 and F21) presented colorectal cancer at young age and most of the at-risk degree relatives developed colorectal cancers and other HNPCC-related cancers at an average age of 51.5 years old.

\section{DISCUSSION}

This is the first study to show the gene mutations and SNPs in Malay HNPCC families and our results showed that the segregation patterns of the variants varied among the six families studied. Several mutations and polymorphisms have been reported in the Malaysian population for the two major genes which cause HNPCC; MLH1 and MSH2. ${ }^{17,26}$ One study on Malaysian HNPCCs by Zahary et al. (2012) found three mutations in the MSH2 gene; c.142G >T (exon 1), c.2005G>C (exon
12) and c.2006-6T>C in intron 12, but these mutations and polymorphisms were not detected in our cohort. In addition, Murad et al. (2012) revealed three mutations in MLH1 and MSH2; C.12G>T in exon 1 and $C .401 T>C$ in exon 3 of the MSH2 gene and c. $451 \mathrm{~A}>\mathrm{C}$ in exon 5 of the MLH1 gene. However, these reported mutations were also not identified in this study cohort.

In this study, the polymorphism in the MLH1 promoter, c. -93G>A was found not to be associated with susceptibility to colorectal cancer. However, this polymorphism has been reported by several studies including in the Malaysian population and it was found to be associated with the susceptibility to sporadic colorectal cancer. ${ }^{11,26}$ The functional effect of this polymorphism remains unclear but two reports have identified this polymorphism as a common promoter variant. ${ }^{10,24}$ The position of this 
polymorphism, located in the promoter region of MLH1, may play a vital role in MLH1 gene transcription, and could further support the association of this polymorphism with the alteration of promoter function. ${ }^{1,19}$ a)

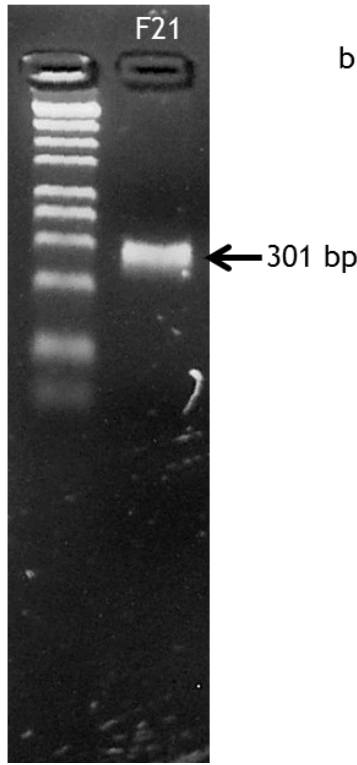

b)

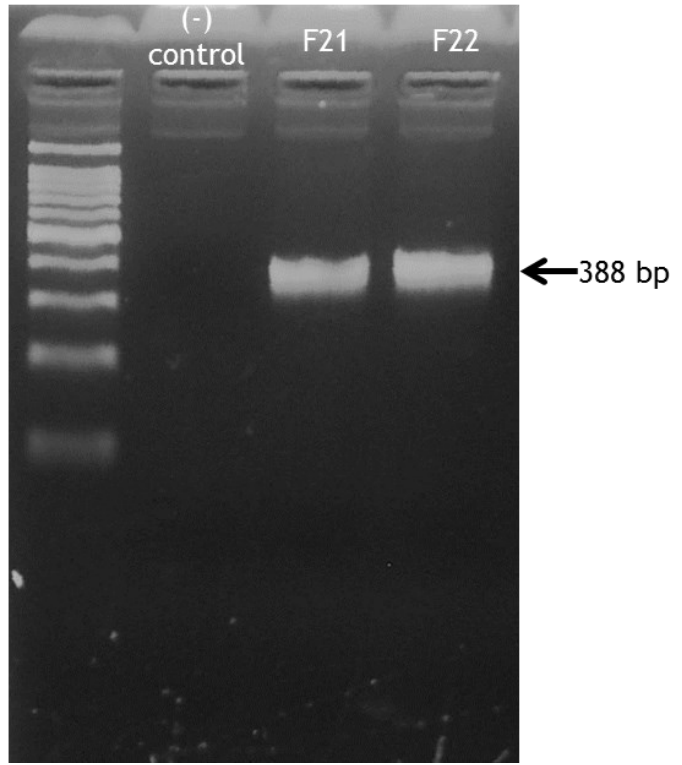

C)

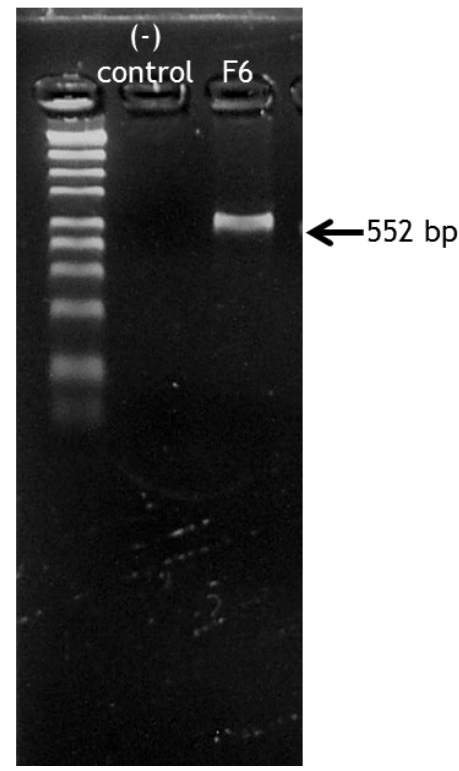

Fig. 2 The gel agarose picture of MSH2 PCR amplification product with its respective expected size of PCR product (bp) for a) intron/exon 5 ; b) intron/exon 1 ; c) intron/exon 3

a)
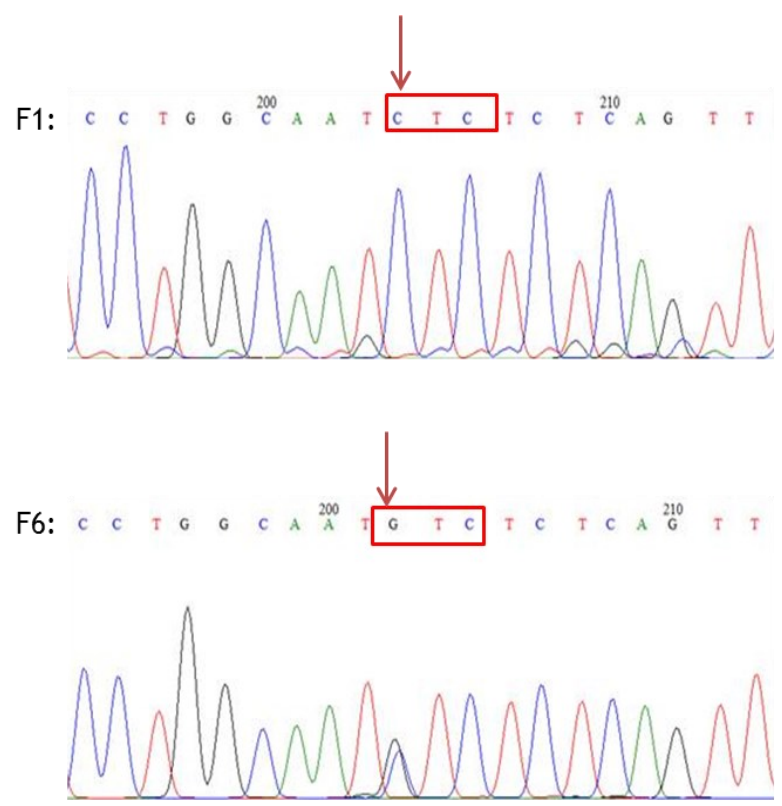

b)
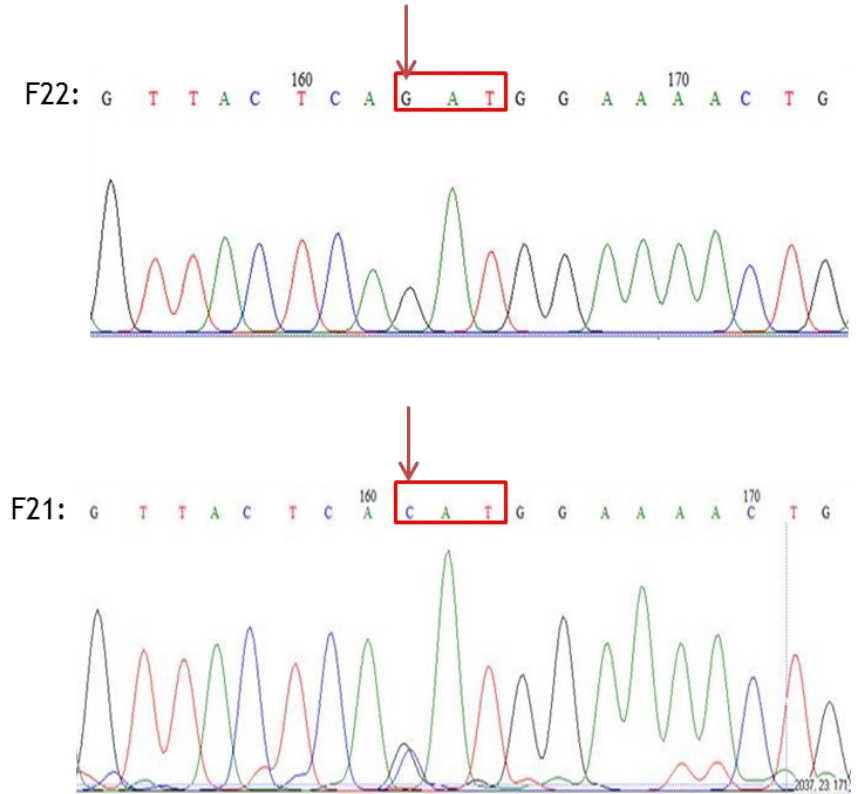

Fig. 3 Sequencing result of two missense mutations showing nucleotide change from a) cytosine $(C)$ to guanine $(G)$ at codon $128(\mathrm{~L} 128 \mathrm{~V})$ resulted in amino acid change leucine (CUC) to be replaced with valine (GUC) in Exon 3 c. 382C $>\mathrm{G}$ (p.Leu128Val); b) guanine (G) to cytosine (C) at codon $132(\mathrm{D} 132 \mathrm{H})$ caused an amino acid change from aspartic acid (GAU) to histidine (CAU) in exon 5 c.394G >C (p.Asp132His) 
a)

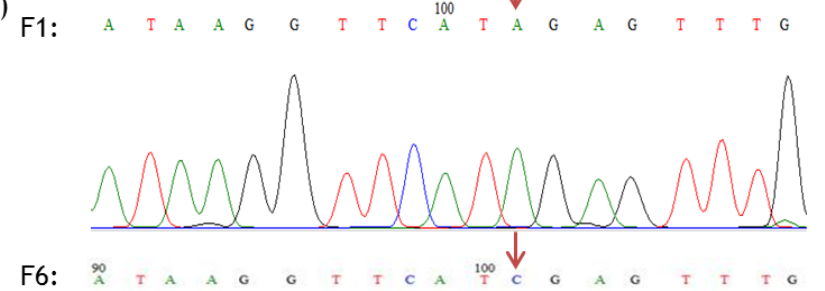

b)
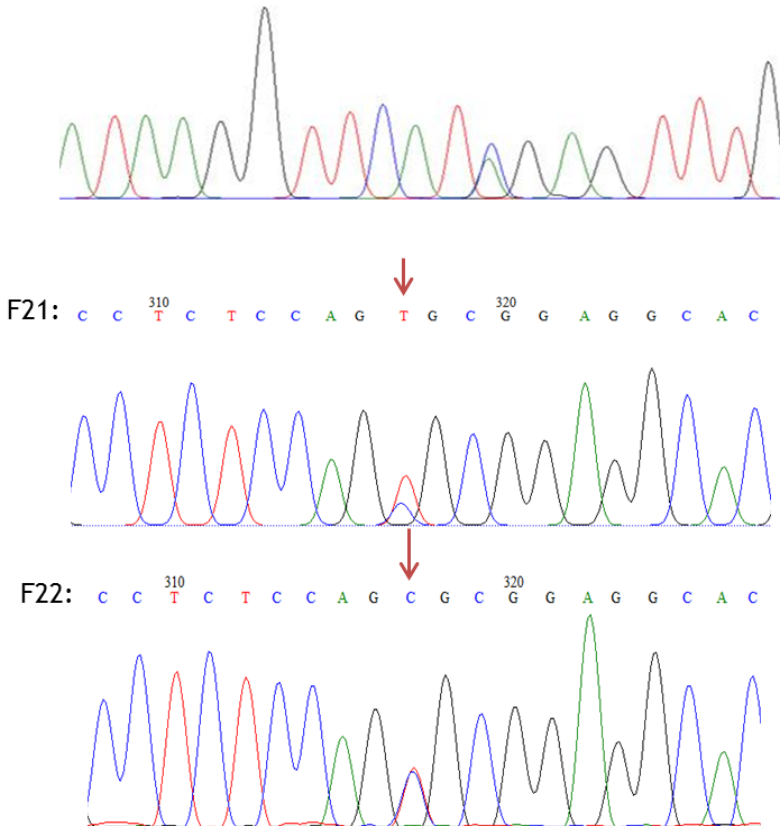

The two SNPs found in intron 1 of the MSH2 gene were known as SNP markers, c. $211+98 \mathrm{C}>\mathrm{T}$ and $\mathrm{c}$. $211+9 C>G^{3}$. Both SNPs were found to be presented with $>20 \%$ heterozygosity in the general population. ${ }^{3}$ In addition, these SNPs were present in the NCBI Single Nucleotide Polymorphism database (dbSNP) with dbSNP ID; rs3815865 (c. $211+98 \mathrm{C}>\mathrm{T}$ ) and rs2303426 $(211+9 C>G)$ respectively ${ }^{30}$ with benign clinical significance according to ClinVar. ${ }^{31}$ High frequencies of allele $\mathrm{G}$ ( $\mathrm{rs} 2303426$ ) in this region was also observed in the East Asian population $(0.81 \%)$ when compared to European $(0.43 \%) .{ }^{30}$ Mangold et al. (2005) have classified MSH2 c. $211+98 \mathrm{C}>\mathrm{T}$ as a frequent polymorphism. Single base substitution which is predicted to be a silent mutation or intronic variant outside the highly conserved splicing region is often found in HNPCC families. ${ }^{20}$

To date, there is are no reports in other populations on the effect of the MSH2 mutation, c.382C $>G$ (p.Leu128Val). The substitution of $C$ to $G$ occurred in codon 128 of exon 3, (CUC to GUC) (Fig. 3a), resulting in amino acid change to valine instead of the normal leucine. The result from the Sorting Intolerant From Tolerant (SIFT) database predicted the variant to be deleterious and damaging with a the score of $0.006 .{ }^{18}$ Based on the Sorting Intolerant From Tolerant (SIFT) database, an amino acid substitution is predicted to be damaging when the score is less or equal to 0.05 and is known to be
C) $\begin{array}{llllllllllllllllllllllll} & \text { F21: } & \text { A } & \text { G } & \underset{G}{220} & \text { T } & \text { G } & \text { A } & \text { G } & \text { G } & \text { G } & \text { C } & \text { C } & \text { G } & \text { G } & \text { G } & \text { A } & \text { C } & \text { G } & \text { G } & \text { C } & \text { G }\end{array}$
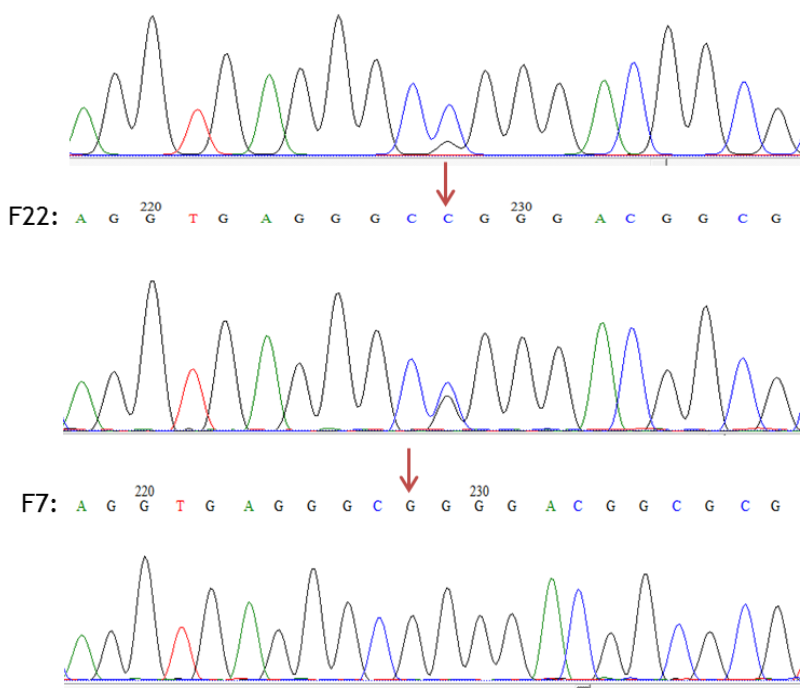

Fig. 4 Sequencing result of three different SNPs in MSH2 gene. a) Different nucleotide change of F1 and F6, c.367 $-86 \mathrm{~A}>\mathrm{C}$ in Family A; b) F21 (daughter) showing similar heterozygous SNP, c.211+98T>C with mother, F22 but with different allele which is T; c) F21 and F22 harboured similar heterozygous SNP c. $211+9 \mathrm{C}>\mathrm{G}$, with allele $\mathrm{C}$, however only $\mathrm{F} 7$ showing allele $\mathrm{G}$.

tolerated if the score is greater than 0.05. According to the COSMIC database, c.382C $>\mathrm{G}$ (p.Leu128Val) could be a missense mutation. ${ }^{2}$ Pagenstecher et al. (2006) have classified the missense mutation to be probably pathogenic when it is not identified in a large number of healthy subjects and involved a highly conserved amino acid. The MSH2 variants also constitute of about $18 \%$ missense variants affecting a single amino acid. ${ }^{5}$ Due to the unavailable tumor block from this patient, immunohistochemical analysis could not be done to determine the $\mathrm{MSH} 2$ protein expression, and our result relied solely on the sequencing analysis.

A mutation in exon 5 of of the MLH1 gene, c. $394 \mathrm{G}>\mathrm{C}$ was predicted to affect the protein function. The nucleotide change of $G$ to $C$ substitution at codon 132 leads to an amino acid change from aspartic acid (GAU) to histidine (CAU) (p.Asp132His) (Fig.3b). The result from the Sorting Intolerant From Tolerant (SIFT) database also predicted the variant to be deleterious and damaging with a score of $0.006 .{ }^{18}$ According to Lipkin et al. (2004) Asp132 is located in a conserved B-hairpin structure which functions as an ATP binding and hydrolysis site as well as to support the 'ATP lid'. The heterodimeric association of MLH1 and PMS2 affects the structure of PMS2 at the end of the 'ATP lid' where the charged residues His139 in PMS2 corresponding to MLH1 Asp132, and Asp119 corresponding to His112 interacts to stabilize the 'ATP lid'. ${ }^{12}$ The substitution of histidine to 
Asp132 interrupts the interaction between Asp132 and His112, destabilizing the 'ATP lid' and alleviating the ATPase activity. ${ }^{12}$ Although polymorphisms in any MMR gene may be a risk factor for colorectal cancer, their functional effects have not delineated in most $\operatorname{cases}^{8}$, and the functional effect of this variant remains contradictory. This variant was thought to be of clinical significance to CRC in Israeli patients ${ }^{12}$, but was reported to be a nonfunctional polymorphism in the Chinese population. ${ }^{16}$

Among the members of the six families studied, only one patient displayed genetic variations in intron 3 and exon 3 of the MSH2 gene. Based on the pedigree of Family A, two members of the family suffered from ovarian cancer including one sister diagnosed with breast cancer and the patient, F1 who suffered from colorectal cancer at the age of 26 (Fig. 1a).According to Watson et al. (2008) ovarian cancer has been reported as the tumour with the second highest incidence rate among $\mathrm{MSH}_{2}$ mutation carriers. In Family F, a patient, F21 was diagnosed with colorectal cancer at the age of 25 years old and her mother suffered from endometrial cancer at the age of 56 years old (Fig. 1b). A mutation in exon 5 of MLH1 gene, c.394G $>C$ (p.Asp132His) was only identified in the daughter (F21). However the daughter died at the age of 26 years old due to advanced rectal cancer with pulmonary embolism.

A variant in intron 3, c. 367-86A $>C$ was also found to be less commonly reported in the literature. Infrequent single base substitutions in the exonic region that do not lead to the change in amino acid or variant in the intronic region outside the highly conserved splice sequences are most probably variants of no functional effect. ${ }^{20}$ In this study, two families were noted to have no mutations and polymorphisms in both genes although the probands, F5 and $\mathrm{F} 10$ with their respective at-risk degree relatives were also diagnosed with colorectal cancer. This could be due to the uncovered exons or introns including other reported genes in HNPCC that may contribute to the defect in the repair function or by the inactivation of the tumor suppressor genes.

Both the SNP, C.367-86A>C in intron 3, and the mutation, $c .382 \mathrm{C}>\mathrm{G}$ in exon 3 , were also searched for in the InSiGHT database, which is known to be the most authoritative database for HNPCC genetic variations. Based on the InSiGHT database search, the SNP, c.367-86A $>C$, and the mutation, c.382C $>$ G were not listed in the database. In this study, the mutation c. $382 \mathrm{C}>\mathrm{G}$ (p.Leu128Val), and the intronic SNP; c.367-86A $>C$, were also found in an ovarian cancer patient. A mutation in the MLH1 gene, c.394G>C, was identified in a young female CRC patient, F21, and although this mutation has been reported before and already listed in the InSiGHT database, this mutation has never been reported in any published study of Malay HNPCC.
Although this current study found no hotspot mutation or in our cohort of HNPCC Malay families, screening of these families revealed five newly discovered genetic variants variants which were identified in more than one family. Two genetic variants were found in the MLH1 genes and four genetic variants were discovered in the $\mathrm{MSH} 2$ genes. The promoter polymorphismvariant, $\quad$. $-93 \mathrm{G}>\mathrm{A}$ is concordant with the previously published report in Malaysian HNPCC patients. A larger and more comprehensive study and analysis is required to determine more conclusively definitively the pathogenic nature of the genetic variants predicted in silico in the current study, including tumour studies to identify concordance studies in tumours with microsatellite instability and/or loss of expression of mismatch repair proteins consistent with the germline change, functional studies of the variants in vitro and/or segregation analysis. By submitting these genetic variants to the international InSiGHT database, we hope to facilitate the interpretation of these variants by an assessment of their risks through the global experience. At present there is insufficient evidence to allow these findings to be used for cascade predictive testing of at risk relatives.

Wan Khairunnisa Wan Juhari and Khairul Bariah Ahmad Amin Noordin co-wrote this manuscript.

\section{ACKNOWLEDGEMENT}

We would like to acknowledge Universiti Sains Malaysia for providing us with a research university grant (1001/PPSP/812112) and the USM APEX grant (1001/PPSP/910343) to conduct the study.

\section{REFERENCES}

1. Arita M, Zhong X., Min Z, et al. Multiple sites required for expression in 5 -flanking region of the hMLH1 gene. Gene, 2003; 306:57-65.

2. Bamford S, Dawson E, Forbes S, et al. The COSMIC (Catalogue of Somatic Mutations in Cancer) database and website. Brit. J. Cancer 2004; vol. 91, pp. 355-358.

3. Bujalkova, M, Zavodna K, Krivulcik T, et al. Multiplex SNaPshot genotyping for detecting loss of heterozygosity in the mismatch-repair genes MLH1 and MSH2 in microsatellite-unstable tumors. Clin. Chem 2008; vol. 54, pp. 1844-1854.

4. Cohen SA \& Leininger A. The genetic basis of Lynch syndrome and its implications for clinical practice and risk management. The Application of Clinical Genetics 2014; vol. 7, pp. 147.

5. Eskander RN, Lynch HT, Brown SM, et al. Novel MSH2 mutation in the first report of a Vietnamese-American kindred with Lynch syndrome. Gynecologic Oncol. Rep. 2015; vol. 12, pp. 31-33.

6. Gala M \& Chung DC. Hereditary colon cancer syndromes. In seminars in oncology 2011; vol. 38, no. 4, pp 490-499. 
7. Geary J, Sasieni P, Houlston R et al. Generelated cancer spectrum in families with hereditary non-polyposis colorectal cancer (HNPCC). Fam. Cancer 2008; 7(2), 163-172.

8. Houlston RS \& Tomlinson IP. Polymorphisms and colorectal tumor risk. Gastroenterology 2001; vol. 121, pp. 282-301.

9. Jasperson KW, Tuohy TM, Neklason DW \& Burt RW. Hereditary and familial colon cancer, Gastroenterology 2010; vol. 138, pp. 2044-2058.

10. Lee SC, Guo JY, Lim R, et al. Clinical and molecular characteristics of hereditary nonpolyposis colorectal cancer families in Southeast Asia, Clin. Genet. 2005; vol. 68, pp. 137-145.

11. Lim KG. A review of colorectal cancer research in Malaysia. Med. J. Malaysia 2014; vol. 69, pp. 23-32.

12. Lipkin SM, Rozek LS, Rennert G, et al. The MLH1 $\mathrm{D} 132 \mathrm{H}$ variant is associated with susceptibility to sporadic colorectal cancer. Nat. Genet. 2004; vol. 36, pp. 694-699.

13. Lynch HT and de la Chapelle A. Genetic susceptibility to non-polyposis colorectal cancer. J. Med. Genet. 1999; vol. 36, pp. 801-818.

14. Lynch HT, Shaw MW, Magnuson CW, et al. Hereditary factors in cancer: study of two large Midwestern kindreds, Arch. Intern. Med. 1966; vol. 117, pp. 206-212.

15. Mangold E, Pagenstecher C, Friedl W, et al. Spectrum and frequencies of mutations in $\mathrm{MSH} 2$ and MLH1 identified in 1,721 German families suspected of hereditary nonpolyposis colorectal cancer. Int. J. Cancer 2005; vol. 116, pp. 692702.

16. Mei Q, Yan HL, Ding FX, et al. Single-nucleotide polymorphisms of mismatch repair genes in healthy Chinese individuals and sporadic colorectal cancer patients. Cancer Genet. Cytogen. 2006; vol. 171, pp. 17-23.

17. Murad NAA, Othman Z, Khalid M, et al. Missense mutations in MLH1, MSH2, KRAS, and APC genes in colorectal cancer patients in Malaysia. Digest. Dis. Sci. 2012; vol. 57, pp. 2863-2872.

18. Ng PC \& Henikoff S. SIFT: Predicting amino acid changes that affect protein function. Nucleic Acids Res. 2003; vol. 31, pp. 3812-3814.

19. Perera S, Mrkonjic M, Rawson JB \& Bapat B. Functional effects of the MLH1-93G>A polymorphism on MLH1/EPM2AIP1 promoter activity. Oncol. Rep. 2011; vol. 25, pp. 809-815.

20. Pagenstecher $C$, Wehner $M$, Friedl $W$, et al. Aberrant splicing in MLH1 and MSH2 due to exonic and intronic variants. Hum. Genet. 2006; vol. 119, pp. 9-22.

21. Pastrello C, Pin E, Marroni F, et al. Integrated analysis of unclassified variants in mismatch repair genes. Genet. Med. 2011; vol. 13, pp. 115 $-124$.

22. Juhari WKW, Rahman WFWA, Sidek ASM, et al. Analysis of Hereditary Nonpolyposis Colorectal Cancer in Malay Cohorts using Immunohistochemical Screening. Asian Pac. J. Cancer P. 2015; vol. 16, pp. 3767-3771.
23. Watson P, Vasen HF, Mecklin JP, et al. The risk of extra-colonic, extra-endometrial cancer in the Lynch syndrome. Int. J. Cancer 2008; vol. 123, pp. 444-449.

24. Wei W, Liu F, Liu L, et al. Distinct mutations in MLH1 and MSH2 genes in hereditary non-polyposis colorectal cancer (HNPCC) families from China. BMB Rep. 2011; vol. 44, pp. 317-322.

25. Ye J, Coulouris G, Zaretskaya I, et al. PrimerBLAST: a tool to design target-specific primers for polymerase chain reaction. BMC bioinformatics 2012; vol. 13, pp. 1.

26. Zahary, M.N., Kaur, G., Hassan, M.R.A., et al. Germline mutation analysis of MLH1 and MSH2 in Malaysian Lynch syndrome patients, World J. Gastroenterology: WJG, 2012, vol. 18, pp. 814.

27. Hall, T. (2011). BioEdit: an important software for molecular biology. GERF Bull Biosci, 2(1), 6.

28. Pruitt, K. D., Tatusova, T., \& Maglott, D. R. (2005). NCBI Reference Sequence (RefSeq): a curated non-redundant sequence database of genomes, transcripts and proteins. Nucleic acids research, 33(suppl 1), D501-D504.

29. Frézal, J. (1998). Genatlas database, genes and development defects.Comptes Rendus de l'Académie des Sciences-Series III-Sciences de la Vie,321(10), 805-817. http:// genatlas.medecine.univ-paris5.fr/

30. Sherry ST, Ward M, Sirotkin K. dbSNP-database for single nucleotide polymorphisms and other classes of minor genetic variation. Genome Res. 1999;9(8):677-679

31. Landrum, M. J., Lee, J. M., Riley, G. R., Jang, W., Rubinstein, W. S., Church, D. M., \& Maglott, D. R. (2014). ClinVar: public archive of relationships among sequence variation and human phenotype. Nucleic acids research, 42 (D1), D980-D985. 